\title{
High-throughput sequencing reveals drastic changes in fungal communities in the phyllosphere of Norway spruce (Picea abies) following invasion of the spruce bud scale (Physokermes piceae)
}

\author{
Running title: Impact of invasive Physokermes piceae
}

Audrius Menkis ${ }^{1 *}$, Adas Marčiulynas ${ }^{2}$, Artūras Gedminas ${ }^{2}$, Jūratė Lynikiené ${ }^{2}$, Aistè Povilaitiené ${ }^{2}$

${ }^{1}$ Department of Forest Mycology and Plant Pathology, Uppsala BioCenter, Swedish University of Agricultural Sciences, P.O. Box 7026, SE-75007 Uppsala, Sweden

${ }^{2}$ Institute of Forestry, Lithuanian Research Centre for Agriculture and Forestry, Liepu str. 1, Girionys, LT-53101 Kaunas district, Lithuania

*Corresponding author: email: Audrius.Menkis@ slu.se ; telephone: +46-18-672729; fax: +46-18-673599

\begin{abstract}
The aim of this study was to assess diversity and composition of fungal communities in damaged and undamaged shoots of Norway spruce (Picea abies) following recent invasion of the spruce bud scale (Physokermes piceae) in Lithuania. Sampling was done in July 2013 and included 50 random lateral shoots from 10 random trees in each of five visually undamaged and five damaged 40-50 years-old pure stands of $P$. abies. DNA was isolated from 500 individual shoots, subjected to amplification of the internal transcribed spacer of fungal ribosomal DNA (ITS rDNA), barcoded and sequenced. Clustering of 149426 high-quality sequences resulted in 1193 non-singleton contigs of which 1039 (87.1\%) were fungal. In total, there were 893 fungal taxa in damaged shoots and 608 taxa in undamaged shoots $(\mathrm{p}<0.0001)$. Furthermore, $431(41.5 \%)$ fungal taxa were exclusively in damaged shoots, 146 $(14.0 \%)$ were exclusively in undamaged shoots and $462(44.5 \%)$ were common to both types of samples. Correspondence analysis showed that study sites representing damaged and undamaged shoots were separated from each other, indicating that in these fungal communities were largely different, and therefore heavily affected by $P$. piceae. In conclusion, the results demonstrated that invasive alien tree pests may have a profound effect on fungal mycobiota associated with the phyllosphere of $P$. abies, and therefore, in addition to their direct negative effect owing physical damage of the tissue, they may also indirectly determine health, sustainability and ultimately distribution of the forest tree species.
\end{abstract}

Keywords: forest health, pathogens, pest insects, climate change, fungal community

\section{Introduction}

Norway spruce (Picea abies) is one of the dominant tree species distributed in a larger part of the north temperate and boreal forests of Europe, and therefore is of tremendous socioeconomic importance [33]. It appears that the climate has been the major determinant of the distributional limits of the tree species and these limits track climate change so closely that even short-term climatic variation can lead to significant range adjustments with consequences for practical forestry and society [39]. The recent observations suggest that the range limit of $P$. abies has begun to change more rapidly than in the past, and a further projection predicts its range expansion in the north and much greater contraction in the south of the present limit [3]. Climate change can affect forests directly (storms, droughts, high 
temperatures) and indirectly (fires, attacks by herbivores, insects and diseases) even the physiological mechanism for the climatic control of $P$. abies is not totally understood [37].

Fungi represent the largest microbial component associated with the living trees and may influence diverse physiological processes including tree diseases and their biological control, and functioning of endophytic and epiphytic symbioses in the phyllosphere. Although fungi play key roles in forest ecosystems including carbon, nutrient and water cycles and may determine forest health and sustainability, the lack of knowledge on their biodiversity, function and adaptation mechanisms to different environmental conditions is a great drawback in the future projections about the consequences of climate change. Another important issue associated with the climate change is arrival and establishment of new and invasive tree pests and diseases which have been reported at an increasing rate and are predicted to be even more frequent in the future [31, 36].

One example is a recent arrival and outbreak of the spruce bud scale (Physokermes piceae) which was observed in Lithuania in 2010 resulting in ca. 7700 ha of heavily damaged $P$. abies stands [8]. Approximately at the same time, $P$. piceae incidences were also reported from the neighbouring Latvia [23] indicating a rapid expansion of this pest northwards though until recently $P$. piceae was mainly known from the central and southern regions of Europe including Slovakia [14], Serbia [9], Hungary [15], Romania [16] and Poland [17]. Physokermes piceae (Coccidae, Hemiptera) damages spruce (Picea spp.) trees of all ages by sucking sap of the needles and of young shoots, and not only weakens the trees by causing premature yellowing and needle cast, dieback of small branches and tops, but also creates conditions for the parasitic fungus Rhizosphaera kalkhoffii infections, which through the wounds infects needles, buds and twigs [2]. In addition, at the feeding sites of $P$. piceae, the needles are coated with honeydew, on which the sooty mold gets established and prevents photosynthesis and respiration processes, and further weakens already damaged trees. Such trees are often attacked by the bark beetles and in particular suffer from so-called winter drought when trees lack water for evaporation [2]. Although it appears that ecology of $P$. piceae and of several fungal taxa is closely associated, the impact of $P$. piceae on fungal diversity and community composition remains unclear. A recent development of highthroughput sequencing methods [30] provide powerful tools to explore fungal diversity [4]. Such tools enable identification of complex fungal communities and individual community components even at low abundances. Besides, while providing detailed and semi-quantitative information, they also enable to study effects of different factors on diversity and composition of fungal communities [21].

The aim of the present study was by using high-throughput sequencing to assess diversity and composition of fungal communities in damaged and undamaged needles and shoots of $P$. abies following attacks of $P$. piceae. We hypothesised that fungal diversity and community composition associated with needles and shoots of $P$. abies is heavily affected by $P$. piceae and thereby differ in damaged vs. undamaged shoots.

\section{Materials and Methods}

Study sites and sampling

This study included ten study sites representing five visually undamaged and five heavily damaged 40-50 years-old pure $P$. abies stands in Lithuania (Fig. 1, Table1). All damaged stand were characterised by a high activity of $P$. piceae and their typical symptoms of damage (see Introduction) in the canopies. Undamaged stands were stands showing no signs of $P$. piceae attacks (presence of insects and/or symptoms of damage in the canopies) and 
were situated at the distance between 200 and $500 \mathrm{~m}$ from respective damaged stands (Fig. 1, Table 1). Sampling was carried out during first two weeks of July 2013. In each stand, ten random trees were selected and from each tree five random present-year lateral shoots (ca. 10 $\mathrm{cm}$-long) with needles were sampled with secateurs from the lower part (approximately $3-5$ $\mathrm{m}$ above the ground) of the canopies. By this, 50 shoots were sampled in each forest stand resulting in 500 altogether (Table 1). Sampled shoots were packed individually into the plastic bags, transported to the laboratory and stored at $-20^{\circ} \mathrm{C}$.

\section{DNA isolation, amplification and sequencing}

Genomic DNA was isolated from 500 individual shoot samples. Prior to isolation of DNA, each shoot with needles was placed in $50-\mathrm{mL}$ centrifugation tubes and freeze-dried at $-60^{\circ} \mathrm{C}$ for 2 days. No surface sterilisation was carried out. Then, shoots were cut into smaller fractions and $1 \mathrm{~g}$ (dry weight) of each shoot material was placed into a 2-mL screw-cap centrifugation tube together with glass beads, and homogenized using a Fast prep shaker (Precellys 24, Bertin Technologies, Rockville, MD). $800 \mu \mathrm{L}$ of extraction CTAB buffer (3\% cetyltrimethylammonium bromide, $2 \mathrm{mM}$ EDTA, $150 \mathrm{mM}$ Tris- $\mathrm{HCl}, 2.6 \mathrm{M} \mathrm{NaCl}, \mathrm{pH} 8$ ) was added to each tube and incubated at $65^{\circ} \mathrm{C}$ for $1 \mathrm{~h}$. After centrifugation, the supernatant was transferred to new $1.5 \mathrm{~mL}$ centrifugation tubes and mixed with one volume of chloroform by gentle vortexing. After centrifugation for $8 \mathrm{~min}$ at $10000 \mathrm{rpm}$, the supernatant was precipitated with 2 volumes of cold isopropanol, washed with $70 \%$ ethanol and dissolved in $50 \mu \mathrm{L}$ TE buffer. In addition, isolated DNA was purified using JETquick DNA Clean-Up System (Genomed, Löhne, Germany). In each sample, concentration of genomic DNA was determined using a ND-1000 spectrophotometer (NanoDrop Technologies, Wilmington, DE). Diluted (1-10 ng/ $\mu \mathrm{L})$ genomic DNA samples were amplified separately using the primer pair fITS9 (5'-GAACGCAGCRAAIIGYGA-3') [13] and ITS4 (5'xxxxxxxxTCCTCCGCTTATTGATATGC-3') [40] containing 8-bp sample identification barcodes denoted by $\mathrm{x}$. Using this primer pair, amplified PCR products were estimated to be between 280-420 bp in size and to include larger part of the 5.8S rRNA gene sequences, complete sequences of noncoding ITS2 rRNA region and partial sequences of the 28S rRNA gene. All samples collected within the same study site were amplified using ITS4 primer containing the same barcode, which resulted in a total of ten different barcodes each representing different study site (Table 1). The PCR reactions, $50 \mu \mathrm{L}$ in volume for each shoot sample, were performed using an Applied Biosystems 2720 Thermal Cycler (Applied Biosystems, Carlsbad, CA) using DreamTaq Green DNA polymerase (Thermo Fisher Scientific, Waltham, MA). Blanks were run for controls. The PCR cycle parameters consisted of an initial denaturation at $95^{\circ} \mathrm{C}$ for $2 \mathrm{~min}, 27$ cycles of denaturation at $95^{\circ} \mathrm{C}$ for $30 \mathrm{~s}$, annealing at $55^{\circ} \mathrm{C}$ for $30 \mathrm{~s}$ and extension at $72^{\circ} \mathrm{C}$ for $45 \mathrm{~s}$, followed by a final extension step at $72^{\circ} \mathrm{C}$ for $7 \mathrm{~min}$. The PCR products were analysed on $1 \%$ agarose gels (Agarose D1, Conda, Madrid, Spain) under UV using GelDocTM 2000 gel documentation system (Bio-Rad laboratories, Berkeley, CA). To purify amplicons, these were precipitated in $1 / 10$ volume $3 \mathrm{M}$ $\mathrm{NaAC}$ and 2 volumes $-20^{\circ} \mathrm{C}$ pure ethanol mixture, vortexed for $10 \mathrm{~min}$, incubated for $20 \mathrm{~min}$ at $-70^{\circ} \mathrm{C}$ and centrifuged for $5 \mathrm{~min}$ at $13000 \mathrm{rpm}$. Supernatant was discarded and dried pellets were dissolved in $30 \mu \mathrm{L}$ Milli-Q water. The concentration of purified PCR products was determined using a ND-1000 spectrophotometer (NanoDrop Technologies, Wilmington, DE), and an equimolar mix of all PCR products was used for Ion Torrent sequencing. Construction of the sequencing library and sequencing using a 316 chip as a part of the larger sample was carried out by NGI SciLifeLab (Uppsala, Sweden).

\section{Bioinformatics}


The sequences generated were subjected to quality control and clustering in the SCATA NGS sequencing pipeline (http://scata.mykopat.slu.se). Quality filtering of the sequences included the removal of short sequences ( $<200 \mathrm{bp}$ ), sequences with low read quality, primer dimers and homopolymers, which were collapsed to $3 \mathrm{bp}$ before clustering. Sequences that were missing a tag or primer were excluded. The primer and sample tags were then removed from the sequence, but information on the sequence association with the sample was stored as meta-data. The sequences were then clustered into different taxa using single-linkage clustering based on $98.5 \%$ similarity. The most common genotype (real read) for clusters was used to represent each taxon. For clusters containing two sequences, a consensus sequence was produced. The fungal taxa were taxonomically identified using GenBank (NCBI) database and the Blastn algorithm. The criteria used for identification were: sequence coverage $>80 \%$; similarity to taxon level $98-100 \%$, similarity to genus level $94-97 \%$. Sequences not matching these criteria were considered unidentified and were given unique names as shown in Table 2.

\section{Statistical analyses}

The rarefaction analysis was performed using Analytical Rarefaction v.1.3 available at http://www.uga.edu/strata/software/index.html. The richness of fungal taxa in P. piceae damaged shoots and in undamaged shoots was compared by non-parametric chi-squared tests calculated from the actual number of observations [20]. Differences in relative abundance (estimated as number of sequences) of dominant fungal taxa detected in damaged shoots and in undamaged shoots of different study sites were analysed by one-way analysis of variance (ANOVA) and Tukey's test which provides confidence intervals for all pairwise differences between means [5, 7]. The statistics were computed using Minitab statistical software (Minitab® Inc., 2003). Shannon diversity index and quantitative Sorensen similarity index were used to characterise diversity and composition of fungal communities in different study sites $[19,34]$. Possible impact of $P$. piceae on fungal communities in different study sites was analysed using Correspondence Analysis (CA) in CANOCO 4.5 [38].

\section{Results}

A total of 231407 sequences was generated by Ion Torrent sequencing from the 500 P. abies lateral shoot samples which by barcoding were divided into ten pools each representing different study site (Table 1). However, 81981 sequences did not pass quality control and were excluded. Clustering of the remaining 149426 high-quality sequences (325 bp on average) resulted in 1193 non-singleton contigs and in 3360 singleton contigs which were excluded from the further analyses. Among the non-singletons, $1039(87.1 \%)$ were representing fungi (representative sequences of all fungal non-singletons are available from GenBank under accession numbers KP897167 - KP898205), 145 (12.1\%) plants, 7 (0.6\%) protists and $2(0.2 \%)$ animals. Total numbers of fungal sequences and of different taxa obtained from each study site are shown in Table 1. A plot of fungal taxa from $P$. piceae damaged and undamaged shoots vs. the number of fungal sequences resulted in rarefaction curves that did not reach the asymptote (Fig. 2), indicating that a potentially higher diversity of taxa could be detected with increased sequencing effort. In this study, the detected fungi were $74.7 \%$ Ascomycota, 24.7\% Basidiomycota, 0.3\% Chytridiomycota and $0.3 \%$ Glomeromycota (Supplementary Table 1). The absolute richness of fungal taxa was higher in damaged shoots (893 taxa out of 78832 sequences) than in undamaged shoots (608 out of 31541) (Table 1, Fig. 2), and the chi-squared test showed that the richness of taxa between these datasets differed significantly $(\mathrm{p}<0.0001)$. Identification at least to genus level was successful for $453(43.6 \%)$ out of 1039 of fungal taxa. Information on the 30 most common fungal taxa representing $70.3 \%$ of all fungal sequences is shown in Table 2. Among these, 
however, 13 taxa representing $34.0 \%$ of fungal sequences could not be identified to taxon or genus level and remained unidentified (Table 2). The most common taxa were Unidentified sp. 2168_2 (8.4\%), Phialophora sessilis (6.0\%), Unidentified sp. 2168_4 (5.0\%),

Setomelanomma sp. 2168_7 (4.3\%) and Unidentified sp. 2168_5 (4.2\%) (Table 2). The fungal pathogen $R$. kalkhoffii (3.5\%) was the seventh most common fungus which at variable abundances was detected in all study sites representing both damaged and undamaged shoot samples (Table 2). ANOVA analysis showed that among the 30 most common taxa, abundance of Phialophora sessilis, Unidentified sp. 2168_17, Aureobasidium pullulans and Exobasidium bisporum was significantly higher in damaged shoots than in undamaged shoots ( $\mathrm{p}<0.05)$, while in Unidentified sp. 2168_11 it was significantly higher in undamaged shoots than in damaged shoots $(\mathrm{p}<0.05)$. The abundance of the remaining 25 most common fungal taxa did not differ significantly between damaged vs. undamaged shoots (Table 2). The remaining 1009 fungal taxa were relatively rare and their relative abundances varied between $0.002 \%$ and $0.6 \%$ (Supplementary Table 1 ).

The CA analysis of fungal communities explained 24.2\% variation on Axis 1 and $21.1 \%$ on Axis 2. The CA showed that study sites representing damaged (D1-D5) and undamaged (H1H5) shoot samples were separated from each other on Axis 1 (Fig. 3a), indicating that in these fungal communities were largely different. Among all taxa, $431(41.5 \%)$ were exclusively found in damaged shoots, $146(14.0 \%)$ were exclusively found in undamaged shoots, and $462(44.5 \%)$ were common to both types of samples (Fig. 3b, Supplementary Table 1). Interestingly, fungal taxa detected in both types of samples were more often linked to the damaged shoots than to the undamaged shoots (Fig. 3b) thereby showing their relatively higher abundances in the shoots damaged by $P$. piceae. Sorensen index of similarity of fungal communities was moderate and ranged between 0.45 and 0.71 then compared in all combinations among different D sites, between 0.38 and 0.52 then compared among different $\mathrm{H}$ sites, and between 0.32 and 0.47 then compared among different $\mathrm{D}$ and $\mathrm{H}$ sites. In different study sites, Shannon diversity index of fungal communities was between 2.9 and 4.2 (Table 1).

\section{Discussion}

The results demonstrated that invasion and outbreak of $P$. piceae had a profound effect on diversity and composition of fungal communities in needles and shoots of P. abies (Fig. $2 \&$ 3 ), thereby supporting the hypothesis. The fungi, which were at higher abundances observed in damaged shoots (Table 2, Supplementary Table 1), were likely benefiting from the physical damage of plant tissues, and/or were benefiting from the insect derived honeydew, which even at low abundances was shown to have a strong effect on the performance of microorganisms in the phyllosphere of $P$. abies $[24,35]$. For example, it was shown previously that fungal pathogen $R$. kalkhoffii readily establishes in plant tissues damaged by $P$. piceae [2]. In the present study, abundance of $R$. kalkhoffii was higher in damaged shoots (3.9\%) than in undamaged shoots $(2.5 \%)$ though the difference was not significant (Table 2). Scattolin and Montecchio [32] showed that abundance of $R$. kalkhoffii on P. abies was negatively correlating with abundance of Lophodermium piceae, indicating that the latter fungus may act as a biocontrol agent of $R$. kalkhoffii. In the present study, however, abundance of $L$. piceae was relatively low (0.05\%) (Supplementary Table 1), which probably led to predominant establishment of $R$. kalkhoffii. Among other dominant fungal taxa, plant pathogen Exobasidium bisporum [41] was significantly more abundant in damaged shoots $(1.4 \%)$ than in undamaged shoots $(0.3 \%)$ (Table 2$)$ thereby taking advantage of the damaged tissues. Interestingly, Apiosporium pinophilum which was shown to preferentially establish on plant parts coated with honeydew and cause black sooty mold [2] was not detected or its 
ITS rDNA sequences remained unidentified despite the fact that damaged shoots possessed characteristic symptoms of black sooty mold. Phialophora sessilis, which was the second most common fungus, was shown to cause sooty blotch and flyspeck on different tree species $[1,42]$. In this study, $P$. sessilis was significantly more abundant in damaged shoots than in undamaged shoots (Table 2), suggesting that it was one of the fungi causing symptoms of black sooty mold. Although the source of inoculum for such fungi cannot be established, the possibility should not be excluded that $P$. piceae vector specific fungal community which may readily establish at the sites of damage. This would not be surprising as insect-fungi associations are common in nature $[6,27,28]$. Yet such information is not available for $P$. piceae, but would be of considerable practical importance as due to the ongoing climate change the impact of $P$. piceae can be expected to be even greater in the future.

Different high-throughput sequencing platforms have their advantages and limitations [29]. In the present study, the use of Ion Torrent sequencing revealed a high diversity of fungi associated with the phyllosphere of $P$. abies while sample barcoding allowed their assignment to particular type of samples (damaged and undamaged) as well as to individual study sites (Table 1). The detected richness of fungal taxa were one or two orders of magnitude as compared to similar studies which were based on fungal culturing [18, 25, 26], showing that such detection methods allow in depth analysis of fungal communities, and challenges our understanding of the global fungal diversity [10,11]. Shannon diversity index of fungal communities was high in all study sites (Table 1) repeatedly demonstrating a high efficacy of the detection method. Nevertheless, a large number of detected fungi (also dominant) remained unidentified (Table 2, Supplementary Table 1) showing that the ITS rDNA sequence information available in the public databases is still limited, and that a great number of fungal taxa remain to be isolated and described. Such information is essential for taxonomic comparisons and scientific communication among the independent studies as well as recognising patterns of distribution and inferring ecological roles. As a large number of taxa (e.g. obligate biotrophs) are likely to be uncultivable, the development of the sequencebased classification is of key importance in order to recognize such taxa in rapidly growing environmental sequence data $[12,22]$.

In conclusion, the results demonstrated that needles and shoots of $P$. abies are inhabited by diverse communities of fungi, and that invasive alien tree pests may have a profound effect on these fungal communities, and therefore, in addition to their direct negative effect owing physical damage of the plant tissue, they may also indirectly determine health, sustainability and ultimately distribution of the forest tree species.

\section{Acknowledgements}

This research was funded by the European Regional Development Fund under the Global Grant measure, project no. VP1-3.1-ŠMM-07-K-02-001.

\section{Compliance with Ethical Standards}

The authors declare the compliance of this work with ethical standards. All authors are informed and agreed on the content of this work, and declare no conflicts of interests.

\section{References}

1. Arias MMD, Batzer JC, Harrington TC, Wong AW, Bost SC, Cooley DR, Ellis MA, Hartman JR, Rosenberger DA, Sundin GW, Sutton TB, Travis JW, Wheeler MJ, Yoder KS, Gleason ML (2010) Diversity and biogeography of sooty blotch and 
flyspeck fungi on apple in the eastern and midwestern United States. Phytopathol 100:345-355

2. Ben-Dov Y, Hodgson CJ (1997) Soft scale insects: their biology, natural enemies, and control. Volym 1. Elsevier, The Netherlands

3. Bradshaw RHW, Holmqvist BH, Cowling SA, Sykes MT (2000) The effects of climate change on the distribution and management of Picea abies in southern Scandinavia. Can J For Res 30:1992-1998

4. Buee M, Reich M, Murat C, Morin E, Nilsson RH, Uroz S, Martin F (2009) 454 Pyrosequencing analyses of forest soils reveal an unexpectedly high fungal diversity. New Phytol 184:449-456

5. Chalmers N, Parker P (1989) Fieldwork and statistics for ecological projects, second edition. The Open University, Dorchester

6. Davydenko K, Vasaitis R, Meshkova V, Menkis A (2014) Fungi associated with the red-haired bark beetle, Hylurgus ligniperda (Coleoptera: Curculionidae) in the foreststeppe zone in eastern Ukraine. Eur J Entomol 111:561-565

7. Fowler J, Cohen L, Jarvis P (1998) Practical Statistics for Field Biology, second edition. Wiley, Chichester

8. Gedminas A, Lynikienè J, Marčiulynas A, Bagdžiūnaite A (2015) Effect of Physokermes piceae Schrank. on shoot and needle growth in Norway spruce stands in Lithuania. Balt For In Press

9. Graora D, Spasić R, Mihajlović L (2012) Bionomy of spruce bud scale, Physokermes piceae (Schrank.) (Hemiptera: Coccidae) in the Belgrade area, Serbia. Arch Biol Sci 64 337-343

10. Hawksworth DL (2001) The magnitude of fungal diversity: the 1.5 million species estimate revisited. Mycol Res 105:1422-1431

11. Hawksworth DL (2012) Global species numbers of fungi: are tropical studies and molecular approaches contributing to a more robust estimate? Biodivers Conserv 21:2425-2433

12. Hibbett DS, Taylor JW (2013) Fungal systematics: is a new age of enlightenment at hand? Nature Rev Microbiol 11:129-133

13. Ihrmark K, Bodeker ITM, Cruz-Martinez K, Friberg H, Kubartova A, Schenck J, Strid Y, Stenlid J, Brandstrom-Durling M, Clemmensen KE, Lindahl BD (2012) New primers to amplify the fungal ITS2 region - evaluation by 454-sequencing of artificial and natural communities. Fems Microbiol Ecol 82:666-677

14. Kolar J (2007) The harmful entomofauna of woody plants in Slovakia. Acta Entomol Serb 12:67-79

15. Kosztarab M, Kozar F (1978) Scale insects - Coccoidea. Fauna Hungariae. Akadémiai Kiadó, Budapest

16. Kozar F (1985) New data to the knowledge of scale-insects of Bulgaria, Greece and Rumania (Homoptera: Coccoidea). Phytopathol Entomol Hung 20:201-205

17. Lagowska B (1986) Scale insects (Homoptera, Coccinea) of Roztocze and the Lublin Upland. Bulletin Entomologique de Pologne 56:475-478

18. Livsey S (1995) Ecology of endophytic microfungi in Norway spruce crowns. PhD thesis, Department of Forest Mycology and Pathology, Swedish University of Agricultural Sciences, Uppsala

19. Magurran AE (1988) Ecological diversity and its measurement. Princeton University Press, Princeton, NJ, USA

20. Mead R, Curnow RN (1983) Statistical methods in agriculture and experimental biology. Chapman \& Hall, London, UK 
21. Menkis A, Burokienė D, Gaitnieks T, Uotila A, Johannesson H, Rosling A, Finlay RD, Stenlid J, Vasaitis R (2012) Occurrence and impact of the root-rot biocontrol agent Phlebiopsis gigantea on soil fungal communities in Picea abies forests of northern Europe. Fems Microbiol Ecol 81:438-445

22. Menkis A, Urbina H, James TY, Rosling A (2014) Archaeorhizomyces borealis sp. nov. and a sequence-based classification of related soil fungal species. Fungal Biol 118:943-955

23. Miezite O, Okmanis M, Indriksons A, Ruba J, Polmanis K, Freimane L (2013) Assessment of sanitary conditions in stands of Norway spruce (Picea abies Karst.) damaged by spruce bud scale (Physokermes piceae Schrnk.). iForest 6:73-78

24. Muhlenberg E, Stadler B (2005) Effects of altitude on aphid-mediated processes in the canopy of Norway spruce. Agric For Entomol 7:133-143

25. Müller MM, Hallaksela AM (1998) Diversity of Norway spruce needle endophytes in various mixed and pure Norway spruce stands. Mycol Res 102:1183-1189

26. Müller MM, Hallaksela AM (2000) Fungal diversity in Norway spruce: a case study. Mycol Res 104:1139-1145

27. Persson Y, Vasaitis R, Langstrom B, Ohrn P, Ihrmark K, Stenlid J (2009) Fungi vectored by the bark beetle Ips typographus following hibernation under the bark of standing trees and in the forest litter. Microb Ecol 58:651-659

28. Ploetz RC, Hulcr J, Wingfield MJ, de Beer ZW (2013) Destructive tree diseases associated with ambrosia and bark beetles: black swan events in tree pathology? Plant Dis 97:856-872

29. Quail M, Smith M, Coupland P, Otto T, Harris S, Connor T, Bertoni A, Swerdlow H, $\mathrm{Gu}$ Y (2012) A tale of three next generation sequencing platforms: comparison of Ion Torrent, Pacific Biosciences and Illumina MiSeq sequencers. BMC Genomics 13:341

30. Ronaghi M, Uhlén M, Nyrén P (1998) A sequencing method based on real-time pyrophosphate. Science 281:363-365

31. Santini A, Ghelardini L, De Pace C, Desprez-Loustau ML, Capretti P, Chandelier A, Cech T, Chira D, Diamandis S, Gaitniekis T, Hantula J, Holdenrieder O, Jankovsky L, Jung T, Jurc D, Kirisits T, Kunca A, Lygis V, Malecka M, Marcais B, Schmitz S, Schumacher J, Solheim H, Solla A, Szabo I, Tsopelas P, Vannini A, Vettraino AM, Webber J, Woodward S, Stenlid J (2013) Biogeographical patterns and determinants of invasion by forest pathogens in Europe. New Phytol 197:238-250

32. Scattolin L, Montecchio L (2009) Lophodermium piceae and Rhizosphaera kalkhoffii in Norway spruce: correlations with host age and climatic features. Phytopathol Mediterr 48:226-239

33. Schlyter P, Stjernquist I, Barring L, Jonsson AM, Nilsson C (2006) Assessment of the impacts of climate change and weather extremes on boreal forests in northern Europe, focusing on Norway spruce. Clim Res 31:75-84

34. Shannon CE (1948) A mathematical theory of communication. The Bell System Technical Journal 27:379-423

35. Stadler B, Müller T (1996) Aphid honeydew and its effect on the phyllosphere microflora of Picea abies (L) Karst. Oecologia 108:771-776

36. Stenlid J, Oliva J, Boberg JB, Hopkins AJM (2011) Emerging diseases in european forest ecosystems and responses in society. Forests 2:486-504

37. Sykes MT, Prentice IC (1996) Climate change, tree species distributions and forest dynamics: A case study in the mixed conifer/northern hardwoods zone of northern Europe. Climatic Change 34:161-177 
38. ter Braak CJF, Smilauer P (1998) Canoco reference manual and user's guide to Canoco for Windows: software for canonical community ordination, Version 4. Microcomputer Power, Ithaca, NY, USA

39. Webb T (1986) Is vegetation in equilibrium with climate? How to interpret lateQuaternary pollen data. Vegetatio 67:75-91

40. White TJ, Bruns T, Lee S, Taylor J (1990) Amplification and direct sequencing of fungal ribosomal RNA genes for phylogenetics. In: Innis MA, Gelfand DH, Sninsky JJ, White TJ (eds) PCR protocols: A guide to methods and applications. Academic Press, Inc., San Diego, USA, pp 315-322

41. Zhang X (1998) A study on the taxonomy of Exobasidium spp. according to fuzzy analysis of cultural properties and the analysis of $28 \mathrm{~S}$ rDNA-PCR-RFLP. Scientia Silvae Sinicae 34:59-71

42. Zhuang JL, Zhu MQ, Zhang R, Yin H, Lei YP, Sun GY, Gleason ML (2010) Phialophora sessilis, a species causing flyspeck signs on bamboo in China. Mycotaxon 113:405-413

Table 1. Studied Picea abies forest stands in Lithuania and detected diversity of phyllosphere fungi

\begin{tabular}{|c|c|c|c|c|c|c|}
\hline Stand & Location & $\begin{array}{l}\text { Health } \\
\text { status* }\end{array}$ & $\begin{array}{l}\text { No. of } \\
\text { trees } \\
\text { sampled }\end{array}$ & $\begin{array}{l}\text { No. of lateral } \\
\text { shoots } \\
\text { sampled }\end{array}$ & $\begin{array}{l}\text { No. of fungal } \\
\text { sequences/taxa } \\
\text { detected }\end{array}$ & $\begin{array}{l}\text { Shannon } \\
\text { diversity } \\
\text { index }\end{array}$ \\
\hline D1 & 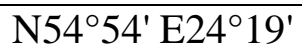 & Damaged & 10 & 50 & $9467 / 276$ & 3.5 \\
\hline D2 & $\mathrm{N} 54^{\circ} 56^{\prime} \mathrm{E} 24^{\circ} 20^{\prime}$ & & 10 & 50 & $17931 / 355$ & 3.5 \\
\hline D3 & $\mathrm{N} 54^{\circ} 49^{\prime} \mathrm{E} 24^{\circ} 20^{\prime}$ & & 10 & 50 & $17019 / 548$ & 4.2 \\
\hline D4 & $\mathrm{N} 56^{\circ} 02^{\prime} \mathrm{E} 22^{\circ} 46^{\prime}$ & & 10 & 50 & $18538 / 531$ & 4.1 \\
\hline D5 & $\mathrm{N} 55^{\circ} 32^{\prime} \mathrm{E} 23^{\circ} 05^{\prime}$ & & 10 & 50 & $15877 / 333$ & 2.9 \\
\hline All D & & & 50 & 250 & $78832 / 893$ & \\
\hline H1 & 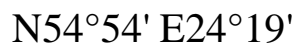 & Undamaged & 10 & 50 & $2372 / 199$ & 3.9 \\
\hline $\mathrm{H} 2$ & $\mathrm{~N} 54^{\circ} 55^{\prime} \mathrm{E} 24^{\circ} 19^{\prime}$ & & 10 & 50 & $5356 / 265$ & 3.5 \\
\hline H3 & $\mathrm{N} 54^{\circ} 49^{\prime} \mathrm{E} 24^{\circ} 02^{\prime}$ & & 10 & 50 & $9435 / 245$ & 3.5 \\
\hline $\mathrm{H} 4$ & $\mathrm{~N} 56^{\circ} 01^{\prime} \mathrm{E} 22^{\circ} 47^{\prime}$ & & 10 & 50 & $7159 / 242$ & 3.3 \\
\hline H5 & $\mathrm{N} 55^{\circ} 32^{\prime} \mathrm{E} 23^{\circ} 05^{\prime}$ & & 10 & 50 & $7219 / 264$ & 3.2 \\
\hline All H & & & 50 & 250 & $31541 / 608$ & \\
\hline All & & & 100 & 500 & $110373 / 1039$ & \\
\hline
\end{tabular}

* Damaged stands were stands heavily attacked by Physokermes piceae; Undamaged stands were stands showing no signs of $P$. piceae attacks. 
Table 2. Occurrence and relative abundance of the 30 most common fungal taxa (shown as a proportion of all fungal sequences) in damaged and undamaged needles/shoots of Picea abies.

\begin{tabular}{|c|c|c|c|c|c|c|c|c|c|c|c|c|c|c|c|c|}
\hline \multirow[t]{2}{*}{ Taxon } & \multirow[t]{2}{*}{ Phylum } & \multirow{2}{*}{$\begin{array}{l}\text { NCBI } \\
\text { reference } \\
\text { sequence }\end{array}$} & \multirow{2}{*}{$\begin{array}{l}\text { Sequence } \\
\text { similarity, } \\
(\%) *\end{array}$} & \multicolumn{6}{|c|}{ Damaged shoots } & \multicolumn{6}{|c|}{ Undamaged shoots } & \multirow[t]{2}{*}{ All } \\
\hline & & & & D1 & D2 & D3 & D4 & D5 & All D & H1 & $\mathrm{H} 2$ & H3 & $\mathrm{H} 4$ & H5 & All H & \\
\hline Unidentified sp. 2168_2 & Ascomycota & FJ820734 & $316 / 320(99)$ & 4.1 & 3.6 & 4.1 & 5.2 & 40.6 & 11.6 & 1.0 & 0.7 & 0.1 & 0.8 & 0.7 & 0.6 & 8.4 \\
\hline Phialophora sessilis & Ascomycota & EU514700 & $339 / 344(99)$ & 17.8 & 11.0 & 1.9 & 2.0 & 10.3 & 7.6 & 2.3 & 3.4 & 0.4 & 2.6 & 1.8 & 1.9 & 6.0 \\
\hline Unidentified sp. 2168_4 & Ascomycota & JX243908 & $311 / 334(93)$ & 4.3 & 8.5 & 2.2 & 2.1 & 0.8 & 3.6 & 7.5 & 13.5 & 4.8 & 7.8 & 11.3 & 8.6 & 5.0 \\
\hline Setomelanomma sp. $2168 \_7$ & Ascomycota & AF525674 & $287 / 302(95)$ & 0.3 & 0.6 & 0.4 & 0.0 & 0.2 & 0.3 & 6.8 & 13.6 & 0.0 & 24.2 & 25.7 & 14.2 & 4.3 \\
\hline Unidentified sp. 2168_5 & Ascomycota & AB476541 & $324 / 328(99)$ & 0.8 & 0.1 & 11.9 & 11.5 & 0.4 & 5.5 & 2.7 & 0.6 & 0.3 & 0.5 & 2.5 & 1.1 & 4.2 \\
\hline Cladosporium cladosporioides & Ascomycota & KJ589639 & $303 / 308(98)$ & 6.1 & 11.8 & 1.0 & 1.1 & 1.9 & 4.3 & 2.1 & 3.2 & 2.6 & 1.5 & 1.3 & 2.1 & 3.7 \\
\hline Rhizosphaera kalkhoffii & Ascomycota & HQ115656 & $318 / 322(99)$ & 3.2 & 10.6 & 1.5 & 1.1 & 2.7 & 3.9 & 1.9 & 2.5 & 0.5 & 4.9 & 3.1 & 2.5 & 3.5 \\
\hline Unidentified sp. 2168_9 & Ascomycota & GU566235 & $291 / 315(92)$ & 1.1 & 6.4 & 0.2 & 0.1 & 0.0 & 1.7 & 3.2 & 8.6 & 0.4 & 12.1 & 9.9 & 6.8 & 3.1 \\
\hline Ceramothyrium sp. 2168_10 & Ascomycota & КС978733 & $307 / 316(97)$ & 0.7 & 0.1 & 7.3 & 7.4 & 1.1 & 3.7 & 5.1 & 1.2 & 0.1 & 0.2 & 1.8 & 1.1 & 2.9 \\
\hline Unidentified sp. 2168_13 & Ascomycota & HQ433032 & $301 / 321(94)$ & 0.0 & - & 4.6 & 2.9 & 0.6 & 1.8 & 0.3 & 1.0 & 14.3 & 2.5 & 0.0 & 5.1 & 2.7 \\
\hline Unidentified sp. 2168_11 & Ascomycota & KF617768 & $280 / 306(92)$ & 0.0 & - & 0.7 & 0.3 & 0.0 & 0.2 & 10.9 & 13.4 & 10.1 & 3.2 & 7.0 & 8.4 & 2.6 \\
\hline Fellomyces sp. 2168_14 & Basidiomycota & AJ608659 & $311 / 328(95)$ & 2.0 & 5.7 & 0.3 & 0.6 & 8.1 & 3.3 & 0.2 & 0.2 & - & 0.0 & 0.0 & 0.1 & 2.4 \\
\hline Unidentified sp. 2168_17 & Ascomycota & JX136410 & $294 / 313(94)$ & 4.6 & 2.1 & 1.4 & 2.4 & 1.4 & 2.2 & 0.7 & 2.1 & 1.0 & 2.1 & 3.9 & 2.1 & 2.1 \\
\hline Sydowia polyspora & Ascomycota & KJ589593 & $315 / 318(99)$ & 1.7 & 0.9 & 5.9 & 1.7 & 0.2 & 2.1 & 1.5 & 4.0 & 0.1 & 2.2 & 2.4 & 1.9 & 2.0 \\
\hline Trichomerium sp. 2168_15 & Ascomycota & KP004468 & $319 / 332(96)$ & 0.2 & 1.0 & 5.5 & 4.3 & 0.8 & 2.6 & 1.3 & 0.4 & 0.3 & 0.6 & 0.6 & 0.5 & 2.0 \\
\hline Unidentified sp. 2168_18 & Ascomycota & КС966333 & $300 / 322(93)$ & - & - & 1.1 & 9.9 & - & 2.6 & - & - & - & 0.0 & - & 0.0 & 1.8 \\
\hline Scleroconidioma sp. 2168_22 & Ascomycota & FR837912 & $304 / 321(95)$ & 15.6 & 0.0 & 1.4 & 0.0 & - & 2.2 & 0.1 & 0.1 & - & - & 0.2 & 0.1 & 1.6 \\
\hline Epicoccum nigrum & Ascomycota & JN835210 & 308/311 (99) & 0.2 & 3.7 & 1.3 & 0.8 & 0.3 & 1.4 & 1.7 & 1.7 & 2.8 & 1.1 & 0.9 & 1.7 & 1.5 \\
\hline Aureobasidium pullulans & Ascomycota & KM877470 & $310 / 314(99)$ & 3.9 & 3.1 & 1.1 & 1.2 & 0.1 & 1.7 & 0.7 & 0.6 & 0.9 & 0.6 & 1.1 & 0.8 & 1.4 \\
\hline Unidentified sp. 2168_23 & Ascomycota & КС965703 & $268 / 317(85)$ & - & - & 5.1 & 2.2 & - & 1.6 & 3.4 & - & 0.2 & - & - & 0.3 & 1.2 \\
\hline Exobasidium bisporum & Basidiomycota & AB 180368 & $327 / 333(98)$ & 1.3 & 1.1 & 1.3 & 1.7 & 1.5 & 1.4 & 0.5 & 0.9 & 0.0 & 0.3 & 0.3 & 0.3 & 1.1 \\
\hline Setomelanomma holmii & Ascomycota & AF525675 & 297/301 (99) & - & 0.5 & 0.2 & 0.0 & 0.4 & 0.2 & 1.2 & 0.1 & 9.4 & 0.0 & 0.1 & 2.9 & 1.0 \\
\hline Phaeosphaeria sp. 2168_26 & Ascomycota & KF251182 & 288/306 (94) & 0.1 & 0.1 & 0.0 & 0.0 & - & 0.0 & 0.9 & 1.8 & 8.7 & 0.1 & 0.1 & 3.0 & 0.9 \\
\hline Unidentified sp. 2168_29 & Ascomycota & JF449549 & 291/312 (93) & 0.2 & 0.2 & 2.6 & 2.4 & 0.1 & 1.2 & 0.0 & - & - & - & 0.0 & 0.0 & 0.9 \\
\hline Cryptococcus sp. 2168_30 & Basidiomycota & KM246292 & $290 / 300(97)$ & 3.2 & 2.4 & 0.0 & 0.0 & 0.1 & 1.0 & - & - & - & 0.1 & 0.0 & 0.0 & 0.7 \\
\hline Neosetophoma samarorum & Ascomycota & KF251162 & $306 / 310(99)$ & - & - & - & - & - & - & - & 0.2 & 7.6 & - & - & 2.3 & 0.7 \\
\hline
\end{tabular}


Unidentified sp. 2168_34

Unidentified sp. 216831

Ascomycota

Ascomycota

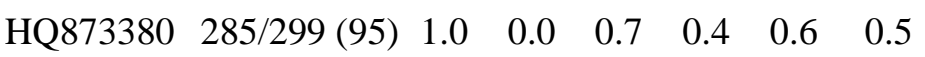

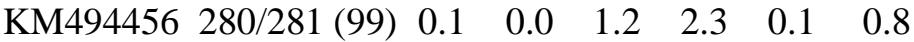

Ascomycota

KJ173536

$\begin{array}{lllll}0.0 & 1.2 & 2.3 & 0.1 & 0.8 \\ 0.1 & 0.0 & 0.0 & 0.0 & 0.0 \\ 0.1 & 0.0 & 0.4 & - & 0.1\end{array}$

$\begin{array}{llllll}0.3 & 1.2 & 0.2 & 0.9 & 2.2 & 1.0\end{array}$

$\begin{array}{llll}0.0 & 0.0 & - & 0.0\end{array}$

0.6

Neosetophoma sp. 2168_40

Ascomycota

$\begin{array}{llllll}\text { FR773250 } & 275 / 296(93) & 0.1 & 0.1 & 0.0 & 0.4\end{array}$

$\begin{array}{lllllll}72.8 & 73.7 & 64.8 & 64.0 & 72.3 & 69.1\end{array}$

$\begin{array}{llllll}- & - & 0.0 & 0.0 & - & 0.0 \\ - & 0.0 & 6.1 & 0.8 & - & 2.0\end{array}$

$\begin{array}{llllll}- & 0.4 & - & 1.5 & 5.9 & 1.8\end{array}$

Unidentified sp. 2168_42

* Sequence similarity column shows base pairs compared between the query sequence and the reference sequence at NCBI databases, and the percentage of sequence similarity in the parenthesis. 


\section{Figure captions}

Figure 1. Map of Lithuania (position shown by shading on the north European map in the lower left corner) showing study sites, in which damaged and undamaged needles/shoots of Picea abies were sampled. Within each site, the distance between damaged and undamaged stands was between 200 and $500 \mathrm{~m}$.

Figure 2. Rarefaction curves showing the relationship between the cumulative number of taxa and the number of ITS rDNA sequences obtained from Physokermes piceae damaged and undamaged shoots of Picea abies.

Figure 3. Ordination diagram based on correspondence analysis of fungal communities showing (a) distribution of different study sites: filled circles - Picea abies stands damaged by Physokermes piceae, and open circles - undamaged stands. Names of the sites are as in Table 1; (b) distribution of different fungal taxa: square - taxa exclusively detected in Picea abies shoots damaged by Physokermes piceae, circle - taxa exclusively detected in undamaged shoots, and cross - taxa detected in both types of samples.

Fig. 1.

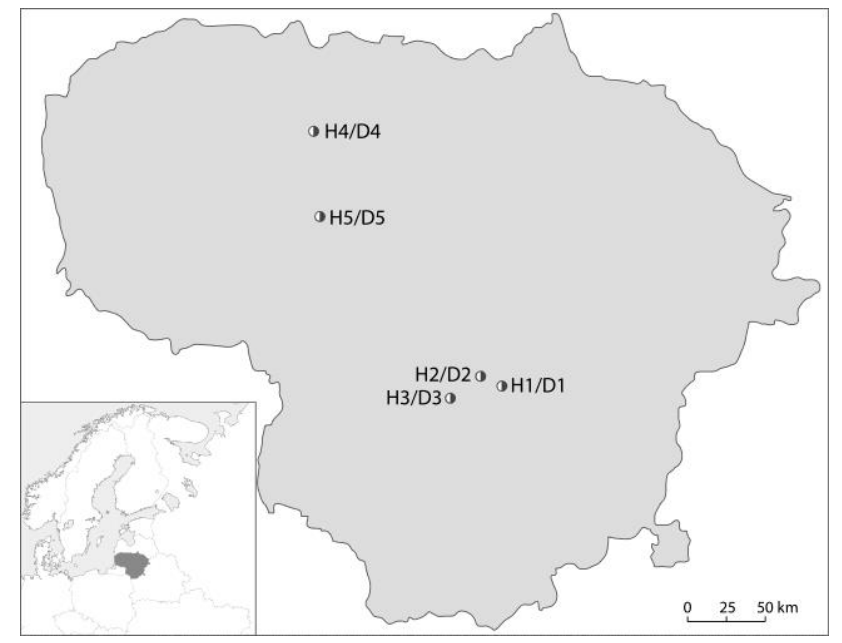

Fig. 2.

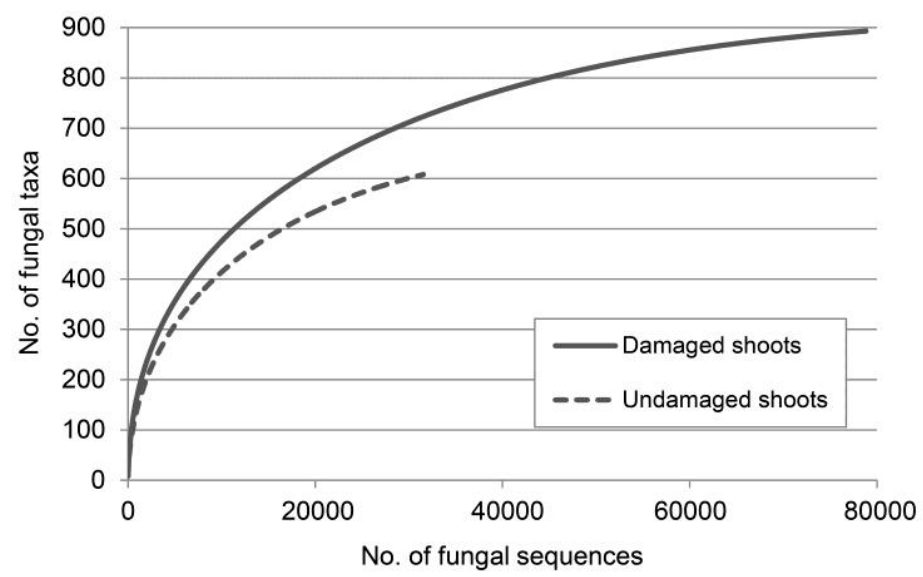


Fig. 3a.

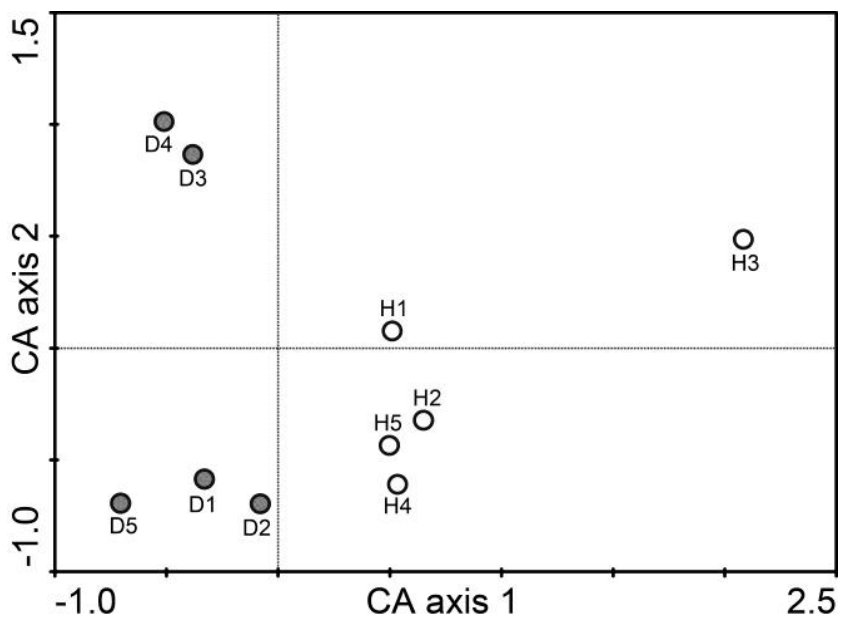

Fig. $3 b$.

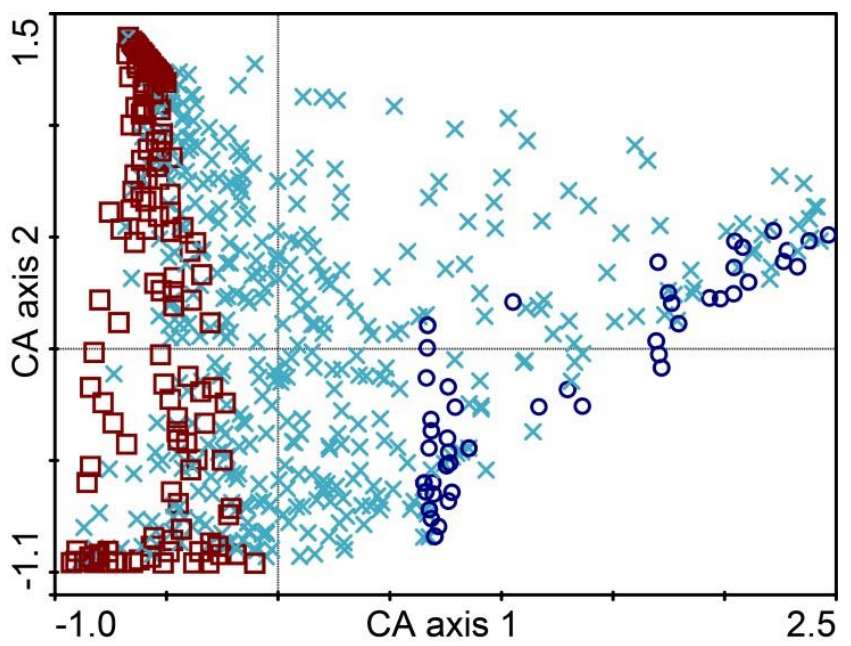

